\title{
Neuroepithelial Cysts Presenting with Movement Disorders: Two Cases
}

\author{
Navraj S. Heran, Caglar Berk, Constantine Constantoyannis, \\ Christopher R. Honey
}

\begin{abstract}
Background: The authors present two cases of movement disorders caused by neuroepithelial cysts and highlight their management. Neuroepithelial cysts are ependymal or epithelial lined fluid collections of unknown etiology within the central nervous system parenchyma with no obvious ventricular or subarachnoid connection. Most cysts are asymptomatic, however, some present with seizures, mass effect, or rarely with movement disorders. Case Reports: The first patient, a 27-yearold female, presented with progressive weakness, dystonic posturing, tremor, ballismus and choreoathetotic movements of her right upper extremity. Her symptoms improved after stereotactic drainage of a neuroepithelial cyst in her basal ganglia but recurred within a year. The second case, a 56year-old female, presented with diplopia, nystagmus, gait imbalance and hemiparesis. Her symptoms improved after stereotactic drainage of a midbrain neuroepithelial cyst. The cyst reaccumulated over the next few years and she became symptomatic with left arm tremor and facial weakness. Aspiration was again performed with symptomatic improvement for nine months. Her tremor recurred and a cyst access device was placed stereotactically. She improved and has remained stable for over a year. Conclusion: Simple stereotactic drainage of neuroepithelial cysts has a high recurrence rate. The authors recommend considering placement of a drainage device to facilitate aspiration of the cyst fluid during follow-up, if needed.
\end{abstract}

RÉSUMÉ: Kystes neuroépithéliaux associés à un désordre du mouvement: présentation de deux cas. Introduction: Les auteurs présentent deux cas de désordres du mouvement causés par des kystes neuroépithéliaux et discutent de leur traitement. Les kystes neuroépithéliaux sont des cavités remplies de liquide, tapissées de cellules épendymales ou épithéliales d'étiologie inconnue dans le parenchyme du système nerveux central, sans connexion ventriculaire ou sous-arachnoïdienne évidente. La plupart des kystes sont asymptomatiques, mais certains patients présentent des crises convulsives, un effet de masse ou rarement un désordre du mouvement. Observation: La première patiente, une femme âgée de 27 ans, a consulté pour une faiblesse progressive, une posture dystonique, du tremblement, du ballisme et des mouvements choréoathétosiques du membre supérieur droit. Ses symptômes se sont améliorés après drainage stéréotaxique d'un kyste neuroépithélial situé au niveau des noyaux gris centraux, mais elle a présenté une récidive des symptômes en dedans d'un an. Le deuxième cas, une patiente âgée de 56 ans, a consulté pour diplopie, nystagmus, déséquilibre à la marche et hémiparésie. Ses symptômes se sont améliorés après drainage stéréotaxique d'un kyste neuroépithélial du mésencéphale. Le kyste s'est reformé de nouveau au cours des années et elle a présenté du tremblement du bras gauche et de la faiblesse des muscles faciaux. Une nouvelle aspiration a été effectuée avec amélioration des symptômes pendant neuf mois. Son tremblement a réapparu et un accès au kyste a été implanté par stéréotaxie. Son état s'est amélioré et elle est demeurée stable pendant plus d'un an. Conclusion: Le drainage stéréotaxique simple de kystes neuroépithéliaux comporte un taux de récidive élevé. Les auteurs recommendent de considérer la mise en place d'un dispositif de drainage pour faciliter l'aspiration du liquide contenu dans le kyste, au besoin.

Can. J. Neurol. Sci. 2003; 30: 393-396

Neuroepithelial cysts are ependymal or epithelial lined fluid collections of unknown etiology within the central nervous system parenchyma with no obvious ventricular or subarachnoid connection. ${ }^{1,2}$ Their fluid content is most similar to that of cerebrospinal fluid (CSF). They are rare congenital anomalies seen in patients without a significant history of infection,
From the Surgical Centre for Movement Disorders, Division of Neurosurgery, University of British Columbia, Vancouver, BC, Canada.

ReCEIVEd March 6, 2003. ACCEPTED In FinAl FORM MAy 27, 2003. Reprint requests to: C.R. Honey, Surgical Centre for Movement Disorders, University of British Columbia, Suite 325, 700 West 10th Avenue, Vancouver, BC, Canada V5Z 4E5 
infarction, hemorrhage, trauma, malignancy, neural tube defects or surgery. ${ }^{3}$ They constitute one-tenth of all intracranial benign cysts, presenting usually in the adult age group and peaking around 20 to 30 years of age. ${ }^{4}$

Most neuroepithelial cysts are asymptomatic, ${ }^{2}$ however some may present with seizures, ${ }^{5,6}$ mass effect ${ }^{7,8,9}$ or rarely with movement disorders. ${ }^{10,11,12}$ They usually present late in their course because of slow growth and lack of pericystic edema. One case of acute hydrocephalus due to hemorrhage into a thalamic cyst has been reported. ${ }^{13}$

The clinical presentation with a movement disorder is particularly uncommon. When it occurs, tremor is most common ${ }^{11,12}$ but hemiballismus has also been reported. ${ }^{10}$ The authors present two cases of movement disorders caused by neuroepithelial cysts. Both improved with treatment of the cyst. Suggestions for management of these lesions are made.

\section{CASe Report}

\section{Case 1}

A 27-year-old, right-handed, First Nations female presented with progressive weakness in her right upper extremity. She complained of stiffness, slowness and involuntary movements of the right arm that had progressed slowly over three years. There was no history of infection, infarction, hemorrhage, trauma, malignancy, surgery, or congenital abnormalities.

Neurological examination revealed normal mental status and cranial nerves. The right upper limb was held in a dystonic posture with the fingers flexed, wrist and elbow extended, and shoulder abducted. She was unable to extend her fingers. There was a coarse tremor at rest that increased with intention. There were occasional choreoathetotic and ballistic movements in the limb. Tone was increased in the affected limb in a lead-pipe manner without cog-wheeling. Bilateral hyperreflexia, more pronounced in the right upper extremity was noticeable. There was mild weakness in the right arm in a pyramidal pattern. Sensory, cerebellar and gait examinations were normal. Computed tomography (CT) demonstrated a $3.0 \mathrm{~cm}$ diameter, well-defined homogeneous CSF density lesion within the left lentiform nucleus without any enhancement or edema (see Figure 1A). The thalamus and subthalamic nucleus were not involved. Mild mass effect was seen on adjacent structures including the internal capsule. Magnetic resonance imaging (MRI) demonstrated the lesion to be well-defined with CSF intensity and no enhancement or edema.

The cyst was punctured stereotactically and $10 \mathrm{ml}$ of clear fluid aspirated. The cyst fluid was consistent with CSF in chemical composition and cytology demonstrated benign appearing, pigmented, stellate cells. Microbiological studies were negative. A postoperative CT scan showed reduction in the cyst size with crenation of its walls (see Figure 1B). A marked reduction in the patient's dystonia, tremor, ballismus and choreoathetosis occurred immediately after surgery. After eight months, both the resting and intention tremor had returned at the pre-operative intensity but the hemiballismus and choreoathetotic movements were still absent. A CT scan showed enlargement of the cyst with a rounded appearance, although not as large as the pre-operative lesion (see Figure 1C). The patient declined further surgery.

\section{Case 2}

A 56-year-old Caucasian female presented with diplopia, left facial weakness and gait imbalance. Deep tendon reflexes were brisk on the left side. A CT scan demonstrated a right midbrain cyst. Stereotactic aspiration and cyst wall biopsy was performed at another institution. Pathology confirmed that the cyst wall was neuroepithelial in origin. Postoperatively her diplopia resolved and gait improved. Annual CT scans showed a slow increase in the cyst's size and by the sixth postoperative year she became symptomatic with diplopia due to subtle right occulomotor paresis and left hemiparesis (see Figure 2A). Her symptoms rapidly progressed over the next three months and she developed a resting and intention tremor in the left upper extremity as well as left facial numbness.

The cyst was drained stereotactically a second time. Postoperatively her left facial numbness, diplopia, hemipareis and her gait imbalance
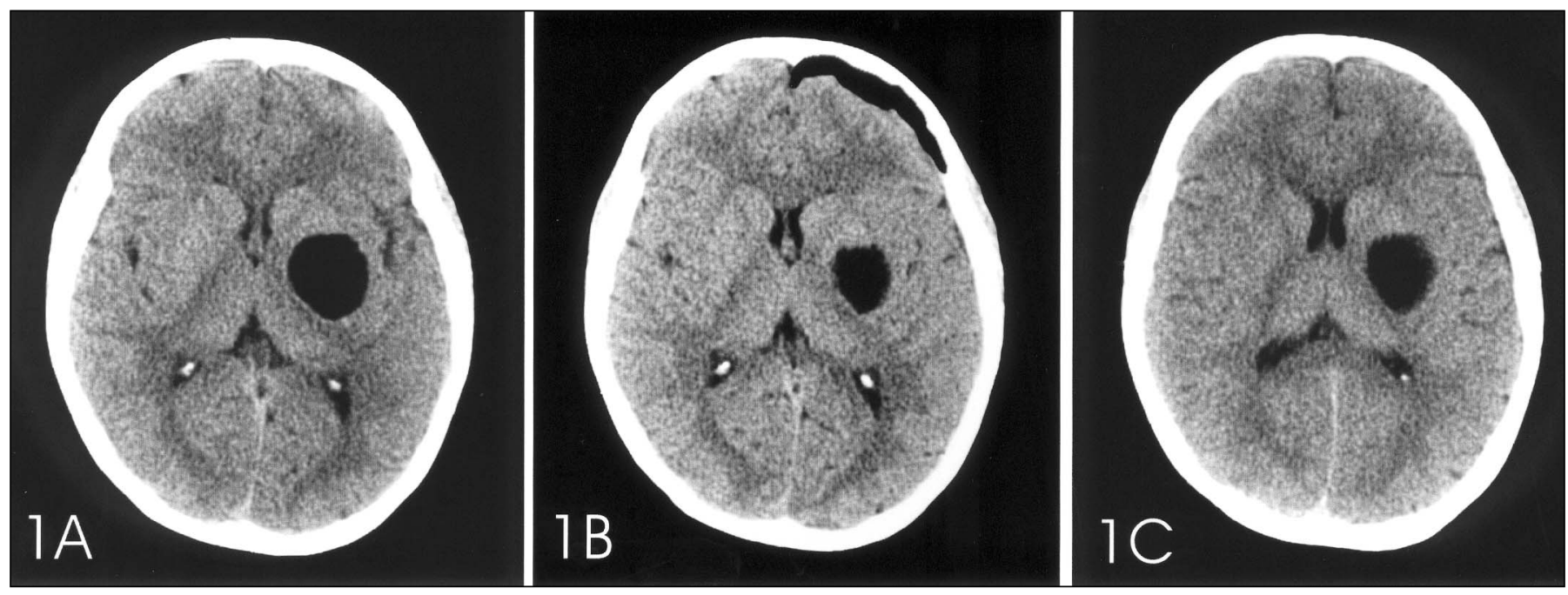

Figure 1: Sequential CT scans for Case 1. A) Pre-operative basal ganglia cyst during acute symptomatic presentation. B) Immediate postoperative imaging demonstrating reduction in cyst size and crenation of its wall. This corresponded to symptomatic improvement. C) Delayed reaccumulation of cyst fluid corresponding to symptomatic worsening. 

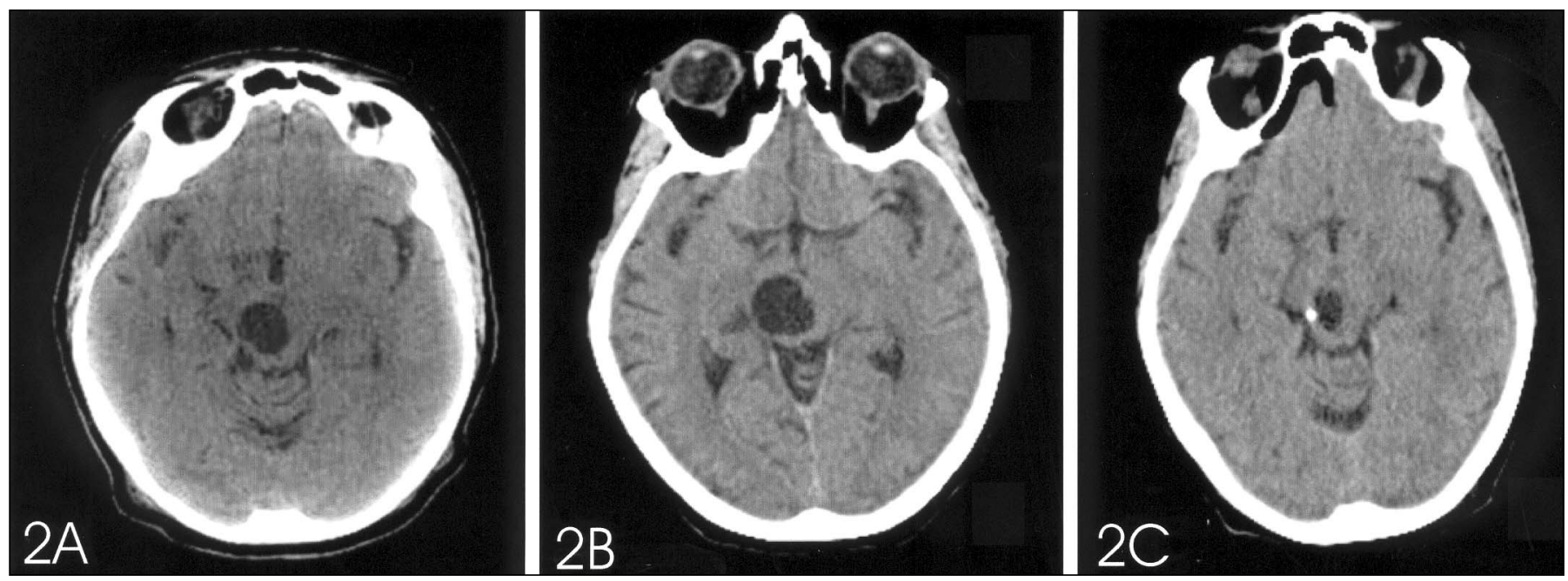

Figure 2: Sequential CT scans for Case 2. A) Imaging prior to second treatment when patient presented with new tremor, facial weakness, diplopia and gait disturbance. B) A year after the second cyst aspiration, the cyst had reaccumulated and was again symptomatic. C) Stable reduction of symptoms followed placement of a ventricular catheter attached to an Ommaya reservoir into the cyst.

improved. The tremor also improved but then worsened during the next year. A CT showed an increase in the cyst's size (Figure 2B) and her upper limb tremor became disabling without any weakness. The tremor was again present at rest and increased with intention. A third aspiration was performed with a permanent ventricular catheter stereotactically inserted into the cyst and connected to an Ommaya reservoir. Her tremor improved postoperatively and has remained stable for over a year. The cyst has remained small (see Figure 2C) in follow-up and appears to be centered in the right red nucleus and does not cross the midline or include the substantia nigra. Any future symptomatic cyst enlargement will be treated in the office with aspiration through the Ommaya reservoir.

\section{Discussion}

Various hypotheses have been proposed regarding the etiology of neuroepithelial cysts. They may develop from arachnoid cell inclusions, tela choroidea-like neural tube segment inclusions, sequestered primitive ependymal cells, or a rupture of the ventricular wall into the brain parenchyma. ${ }^{11}$ The clinical presentation of a neuroepithelial cyst with a movement disorder is particularly uncommon. When it does occur, tremor is the most frequent manifestation ${ }^{11,12}$ as was seen in Case 2. Hemiballismus has also been reported ${ }^{10}$ as seen in Case 1. Our patient with dystonia and choreoathetosis appears to be unique in the literature. Several putative mechanisms for the production of these movement disorders have been advanced although none is universally accepted. ${ }^{14-16}$

Most of these lesions are diagnosed incidentally. ${ }^{2}$ They appear on CT as a well-defined, homogeneous, low-density lesion without any mural component or enhancing areas. ${ }^{17}$ Their MRI appearance reflects a CSF cavity with well-defined borders. ${ }^{5,8}$ They may be septated, but do not have wall enhancement or surrounding edema. ${ }^{5,8}$ Serial imaging, with contrast, may differentiate these lesions from those that are malignant. ${ }^{7}$ If the lesion is stable during follow-up, no further diagnostic studies may be indicated.

A multitude of treatment modalities have been suggested over the years. Conservative follow-up is recommended if the patient is asymptomatic ${ }^{2}$ or the symptoms can be managed medically. ${ }^{5}$ With symptomatic lesions, particularly those with mass effect, surgical management is recommended. Surgical approaches have varied from simple stereotactic aspiration (with or without biopsy), as was done in our two cases initially, to more invasive procedures such as endoscopic fenestration of the cyst to an adjacent CSF space, ${ }^{18}$ placement of an internal cystosubarachnoid or cysto-ventricular shunt, ${ }^{4}$ external drainage reservoir, ${ }^{19}$ cyst resection, or open fenestration into the subarachnoid space or ventricles. ${ }^{10,13}$ Both of our cases demonstrated failure of simple drainage with biopsy suggesting that once the diagnosis of these lesions has been made, a more definitive procedure to treat the inevitable reaccumulation of fluid must be done. A simple option may be the placement of an access reservoir as was done in our second case.

\section{REFERENCES}

1. Gonzalez C, Roda JM, Alvarez F, et al. Supratentorial neuroepithelial cysts. Report of two cases. J Neurosurg Sci 1984; 28: 97-102.

2. Guermazi A, Miaux Y, Majoulet JF, et al. Imaging findings of central nervous system neuroepithelial cysts. Eur Radiol 1998; 8: 618-623.

3. Lustgarten L, Papanastassiou V, McDonald B, et al. Benign intracerebral cysts with ependymal lining: pathological and radiological features. Br J Neurosurg 1997; 11: 393-397.

4. Wester K, Pedersen PH. Benign intracerebral cysts treated with internal shunts: review and report of two patients. Neurosurgery 1992; 30: 432-436.

5. Morioka T, Nishio S, Suzuki S, et al. Choroidal fissure cyst in the temporal horn associated with complex partial seizure. Clin Neurol Neurosurg 1994; 96: 164-167.

6. Tamayo JA, Ojea T, Hervas M, et al. [Neuroepithelial cyst of the 
choroid sulcus as a probable cause of symptomatic focal epilepsy]. Rev Neurol 1997; 25: 2070-2071.

7. Baysefer A, Erdogan E, Gezen F, et al. Cyst of the mesencephalon (neuroepithelial cyst?): review and case report. Minim Invasive Neurosurg 1997; 40: 148-150.

8. Goh RH, Maguire J. Neuroepithelial cyst of the posterior fossa: two case reports with radiologic-pathologic correlation. Can Assoc Radiol J 1996; 47: 126-131.

9. Markwalder TM, Zimmerman A. Intracerebral ciliated epithelial cyst. Surg Neurol 1979; 11: 195-198.

10. Bejar JM, Kepes J, Koller WC. Hemiballism and tremor due to ependymal cyst. Mov Disord 1992; 7: 370-372.

11. Friede RL, Yasargil MG. Supratentorial intracerebral epithelial (ependymal) cysts: review, case reports, and fine structure. J Neurol Neurosurg Psychiatry 1977; 40: 127-137.

12. Rajshekhar V. Benign thalamic cyst presenting with contralateral postural tremor. J Neurol Neurosurg Psychiatry 1994; 57: 11391140.

13. Tokumitsu N, Sako K, Kunimoto M, et al. Glial cyst in the thalamus with intracystic hemorrhage-case report. Neurol Med Chir (Tokyo) 1997; 37: 284-287.

14. Krauss J, Grossman R. Surgery for hyperkinetic movement disorders. In: Jankovic J, Tolosa E (Eds): Parkinson's Disease and Movement Disorders. Philadelphia, Pa: Williams \& Wilkins, 1998; 1017-1048.

15. Krystkowiak P, Martinat P, Defebvre L, et al. Dystonia after striatopallidal and thalamic stroke: clinicoradiological correlations and pathophysiological mechanisms. J Neurol Neurosurg Psychiatry 1998; 65: 703-708.

16. Shannon K. Hemiballismus. Clin Neuropharmacol 1990; 13: 413 425.

17. Nakasu Y, Handa J, Watanabe K. Progressive neurological deficits with benign intracerebral cysts. Report of two cases. J Neurosurg 1986; 65: 706-709.

18. Eiras Ajuria J, Alberdi Vinas J. Endoscopic treatment of intracranial lesions. Apropos of 8 cases. Neurochirurgie 1991; 37: 278-283.

19. Herrera EJ, Caceres M, Viano JC, et al. Stereotactic neurosurgery in children and adolescents. Childs Nerv Syst 1999; 15: 256-261. 